\title{
Energy Absorption Capacity of SBR Latex-Modified Ordinary Portland Cement by Charpy Impact Test
}

\author{
Tri N. M. Nguyen (1) and Jung J. Kim *(1) \\ Department of Civil Engineering, Kyungnam University, Changwon-si 51767, Korea; nnmtri@utc2.edu.vn \\ * Correspondence: jungkim@kyungnam.ac.kr; Tel.: +82-552-496-421; Fax: +82-505-999-2165
}

check for updates

Citation: Nguyen, T.N.M.; Kim, J.J. Energy Absorption Capacity of SBR Latex-Modified Ordinary Portland Cement by Charpy Impact Test. Materials 2021, 14, 2544. https:// doi.org/10.3390/ma14102544

Academic Editors: Weena Lokuge and Chamila Gunasekara

Received: 24 March 2021

Accepted: 4 May 2021

Published: 13 May 2021

Publisher's Note: MDPI stays neutral with regard to jurisdictional claims in published maps and institutional affiliations.

Copyright: (c) 2021 by the authors. Licensee MDPI, Basel, Switzerland. This article is an open access article distributed under the terms and conditions of the Creative Commons Attribution (CC BY) license (https:// creativecommons.org/licenses/by/ $4.0 /)$.

\begin{abstract}
The present study deals with tests on the energy absorption capacity and compressive strength of styrene-butadiene rubber (SBR) latex-modified cementitious materials. Different polymercement ratios $(\mathrm{P} / \mathrm{C})$ of $0,5,10,15$, and $20 \%$ were carried out with the Charpy impact test at 7,14 , and 28 days of curing. The observations showed an increase in the energy absorption capacity of the SBR latex-modified cement paste in correspondence with the increase in curing times, as well as the increase in the $\mathrm{P} / \mathrm{C}$ ratios. The $\mathrm{P} / \mathrm{C}$ ratio of $10 \%$ was the optimal ratio for observing the highest energy absorption capacity of the SBR latex-modified cement paste, with a $43 \%$ increase observed. In addition, a linear relationship between compressive strength and the energy absorption capacity at 28 days was proposed. Based on that, the energy absorption capacity of SBR latex-modified cement paste can be analyzed or predicted by the compressive strength results, regardless of the $\mathrm{P} / \mathrm{C}$ ratios. Finally, the two-parameter Weibull distribution was proved to fit by the observation data from the Charpy impact test.
\end{abstract}

Keywords: energy absorption capacity; SBR latex; Charpy impact test; compressive strength; Weibull distribution

\section{Introduction}

Cement has long been viewed as a widely used material in the construction industry that plays a role as an essential binder in the composition of concrete [1,2]. The failure of concrete in general, and of cement in particular, is an undesirable phenomenon for several different reasons, the most obvious of this being the potential effect on impact loading. Experiments such as the explosive test [3], the projectile impact test [4], the drop-weight impact test [5], and the split Hopkinson pressure bar test [6] have been created to ascertain the dynamic mechanical properties of materials. Among these tests, the Charpy pendulum impact test is most commonly used to evaluate the toughness of the energy absorption capacity of materials [7]. This experiment determines the energy absorbed during the fracturing of materials. It utilizes small-sized specimens and a simple pendulum impact tester, and therefore can be conducted quickly and easily compared to other standard fracture toughness tests, and is much cheaper to use. It is not only utilized and standardized for testing metallic materials (ASTM E23, ISO 148) [8,9] or plastic materials (ASTM D6110, ISO 179) [10,11], but also is applied to composites, ceramics, and polymers [12-14]. In particular, the literature review shows the energy absorption capacity of cement-based materials as measured by the Charpy pendulum impact test [15]. Hakamy et al. [16] found good interfacial bonding between the fibers and nanomatrix, and observed an increase of $23 \%$ in the impact strength of a hemp fabric-reinforced nanoclaycement composite compared to that of a hemp fabric-reinforced cement composite. The work [17] showed through the Charpy impact test the decrease in resistance of a glass fiberreinforced cement containing an acrylic polymer emulsion due to the emulsion reducing the elastic modulus of the cement-based material. In addition, the energy absorption capacity of ultra-high-performance hybrid fiber reinforced concrete has been examined by 
Yu et al. [18]. They found the dominating role that long steel fiber has in improving the Charpy impact resistance of that material.

From another perspective, improving the performance of cement-based materials by a polymer admixture has been conducted since the 1920s [19,20]. The observations showed the positive influence polymer has on improving strength, deformability, workability, durability, and so on. From microstructural investigations, the improving mechanism of the polymer was due to the incorporation of the cement hydration process and polymer film formation in the matrix phase. The work of Ohama [21] found the chemical reactions between polymer particles and calcium-based and silicate-based components of cement. These reactions were expected to improve the bond between the binder and aggregates. In addition, the formation of polymer films showed a positive effect on bridging the microcracks in the matrix under the stressed conditions, leading to a restriction in the propagation of cracks. Overall, these reactions improve the performance of cement-based materials. The literature review showed numerous types of polymers such as styreneacrylate polymer, copolymer of vinyl propionate and vinylidene chloride, acrylate with a coupling agent polymer, ethylene-vinyl acetate copolymer, ethylene-acetate ethylene interpolymer, and so on, have been utilized to improve cement-based materials [22-24]. Recently, styrene-butadiene rubber (SBR) latex has been considered as a beneficial polymer for improving the performance of cement-based materials. From the microstructural perspective, the work [25] found the filling effect of SBR latex led to improving the degree of density of the interfacial transition zone (ITZ). From the cement hydration process perspective, the works [26-28] found the retardation effect of SBR latex on the cement hydration process at an early age, but this inhibiting effect becomes weaker with a long curing period. In addition, the degree of cement hydration decreases with the increase in SBR solid/water ratio up to $20 \%$. From the physical behavior perspective, the fluidity of the cement paste containing SBR latex increased with the increase in latex content $[29,30]$. From the mechanical properties perspective, the observations in the literature showed the decrease in compressive and flexural strengths corresponded with the increase in SBR latex content [31,32]. It is worth mentioning that the polymers themselves exhibited a high impact resistance, therefore, latex-modified cement-based materials were recognized with a good energy absorption capacity compared to the conventional ones [21]. As reviewed above, there are many benefits of SBR latex in regard to improving cement-based materials. However, studies on the energy absorption capacity of SBR latex-modified cement paste have not been carried out. In this study, the energy absorption capacity of SBR latexmodified cement paste was examined by use of the Charpy impact test. Different polymercement ratios (P/C) of $0,5,10,15$, and $20 \%$, as well as different curing times of 7,14 , and 28 days, were considered in this work. In addition, the compressive strength of SBR latex-modified cement paste at 28 days was observed to find the relationship between the compressive strength and the energy absorption capacity of these modified cementitious materials. Finally, the statistical approach was utilized to clarify the observations from the experimental test and the effect of SBR latex on the energy absorption capacity of cement paste.

\section{Experimental Section}

\subsection{Materials and Specimens}

Materials in this study included ordinary Portland cement (Ssangyong Co., Seoul, Korea), type I, compliance with ASTM C150/150M [33], and an emulsion form of sstyrenebutadiene rubber (SBR) latex (JAPT-1520, Jung Ang Polytech Co., Gyeongsangnam, Korea). The physical properties of SBR latex are summarized in Table 1. 
Table 1. Physical properties of SBR latex.

\begin{tabular}{ccccccc}
\hline $\begin{array}{c}\text { TSC } \\
(\%)\end{array}$ & pH & $\begin{array}{c}\text { Sp.gr } \\
\left(\mathbf{K g} / \mathbf{m}^{2}\right)\end{array}$ & $\begin{array}{c}\text { Viscosity } \\
(\mathbf{c p s})\end{array}$ & $\begin{array}{c}\text { Average Particle Size } \\
(\AA)\end{array}$ & $\begin{array}{c}\text { Tg } \\
\left({ }^{\circ} \mathbf{C}\right)\end{array}$ & $\begin{array}{c}\text { MFT } \\
\left({ }^{\circ} \mathbf{C}\right)\end{array}$ \\
\hline 47.0 & $9-11$ & 1090 & $<500$ & 1500 & -1 & -1 \\
\hline
\end{tabular}

TSC: total solid content; Sp.gr: specific gravity; $T_{\mathrm{g}}$ : glass transition temperatures; MFT: minimum film-formation temperature.

The cement paste specimens were prepared with the constant water-cement ratio of 0.4 , and the polymer-cement ratio $(\mathrm{P} / \mathrm{C})$ of $0,5,10,15$, and $20 \%$, respectively. It is worth mentioning that the total solid content (TSC) of latex is $47 \%$, therefore, when determining the amount of SBR latex polymer for the experiment, this factor needed to be considered. The mixture designs are presented in Table 2, in which names of the specimens are marked from SBR00 to SBR20, in that order, for the $\mathrm{P} / \mathrm{C}$ ratios from $0 \%$ to $20 \%$.

Table 2. Mixture design by mass ratio.

\begin{tabular}{cccccc}
\hline Name & SBR00 & SBR05 & SBR10 & SBR15 & SBR20 \\
\hline Cement & 1 & 1 & 1 & 1 & 1 \\
SBR polymer (solid content) & 0 & 0.05 & 0.1 & 0.15 & 0.2 \\
Water & 0.4 & 0.4 & 0.4 & 0.4 & 0.4 \\
\hline
\end{tabular}

All of the specimens were cured in the water under laboratory conditions $\left(20 \pm 20^{\circ} \mathrm{C}\right.$, $50 \pm 5 \%$ R.H). The Charpy specimen was proposed in the form of a $10 \times 10 \times 50 \mathrm{~mm}$ v-notched bar [15]. The specimen dimensions are clarified in Figure 1, where $\beta=45^{\circ}-90^{\circ}$, $\mathrm{a}=2 \mathrm{~mm}, \mathrm{w}=\mathrm{B}=10 \mathrm{~mm}, \mathrm{~L}=50 \mathrm{~mm}$. The tests were conducted after 7,14 , and 28 days of curing.
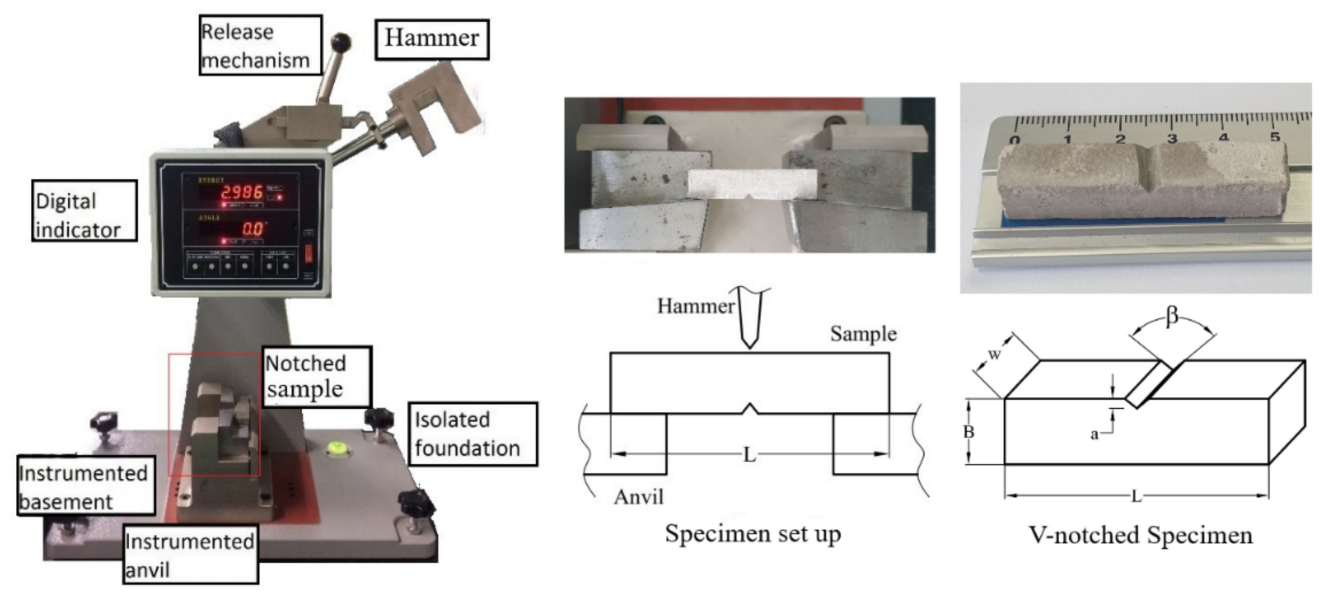

Figure 1. The Charpy impact test.

The specimen for the compressive strength test was a $50 \times 50 \times 50 \mathrm{~mm}$ cube (see Figure 2), complying with the specification of ASTM C 109/109M [34], and the test was conducted at the age of 28 days. 

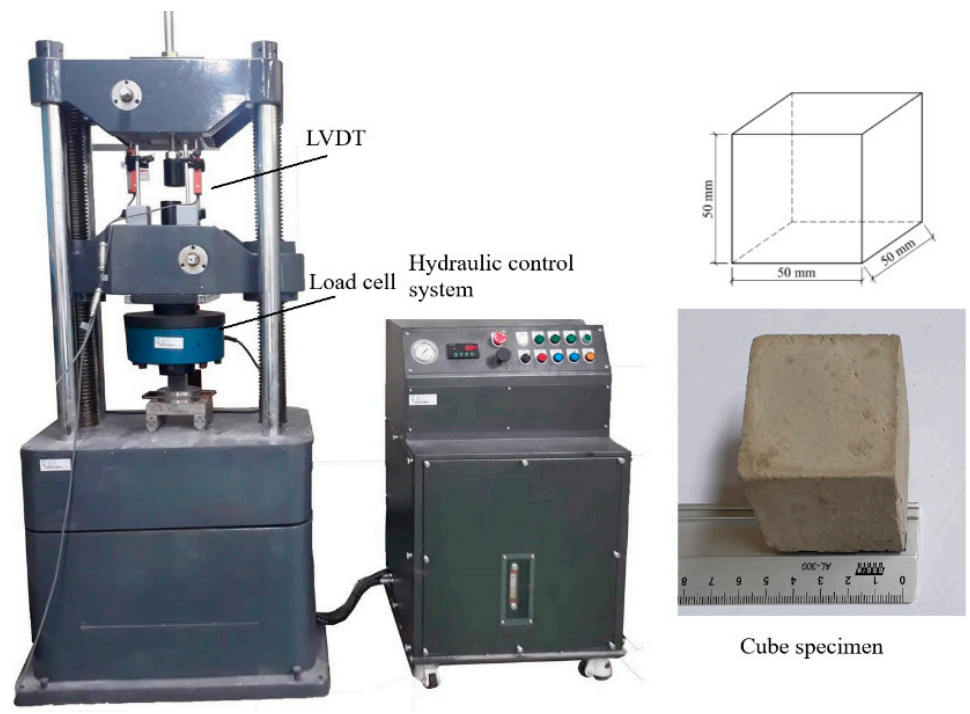

Cube specimen

Figure 2. The compressive strength test.

\subsection{Testing Methods}

The breaking energy of hardened cement paste specimens was observed by the Charpy pendulum impact tester MT-333 (Dong Ah Testing Machine Co., Seoul, Korea). At the initial state, a $0.7 \mathrm{~kg}$ pendulum hammer was attached to the machine body using a pinned rotating arm at a height of $0.435 \mathrm{~m}$, and with a stored energy of $2.986 \mathrm{~J}$. The specimen was supported at both ends by two anvils parted like a simple beam. The fracture occurs after the falling hammer hits, with impacts on the face opposite the notch. It is worth noting that if the pendulum is stopped by the specimen, i.e., the fractured impact specimen does not separate into two parts, the pendulum mass should be increased and the test reconducted [11]. The energy transferred to the material can be inferred by comparing the difference in the height of the hammer before and after a fracture. The breaking energy (J) was recorded, calculated, and shown automatically on the digital display screen (see Figure 1). The energy absorption capacity $\left(\mathrm{J} / \mathrm{m}^{2}\right)$ was determined by dividing the breaking energy by the area of the failure surface. It is worth noting that, in this present work, the failure occurred at the notched sections. Therefore, the failure surface area was assumed as the area of the notched sections. Five samples of each $\mathrm{P} / \mathrm{C}$ ratio were carried out for the Charpy test at 7,14 , and 28 days of curing.

In addition, the compressive strength test was conducted by means of a hydraulic universal testing machine with a capacity of $1000 \mathrm{kN}$, as presented in Figure 2. The test was performed in compliance with the ASTM C109/109M, and 3 specimens for each P/C ratio were examined at the curing age of 28 days. In summarization, 15 cube and $75 \mathrm{v}$-notched bar specimens were tested in this present study.

\section{Results and Discussion}

\subsection{Compressive Strength}

The compressive strength results of the 28-day OPC modified by SBR latex with different $\mathrm{P} / \mathrm{C}$ ratios are given in Figures 3 and 4 , and Table 3 . 


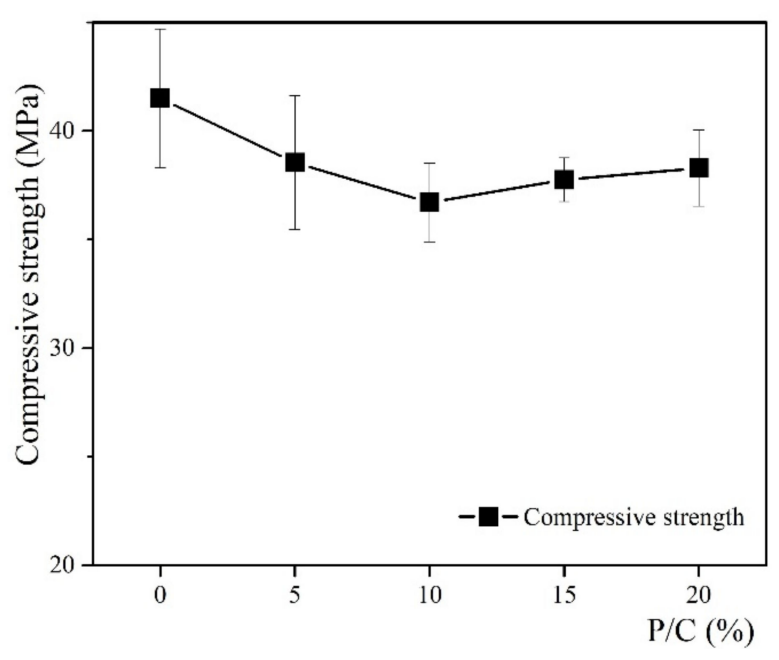

Figure 3. Compressive strength of the SBR latex-modified cement paste at 28 days.

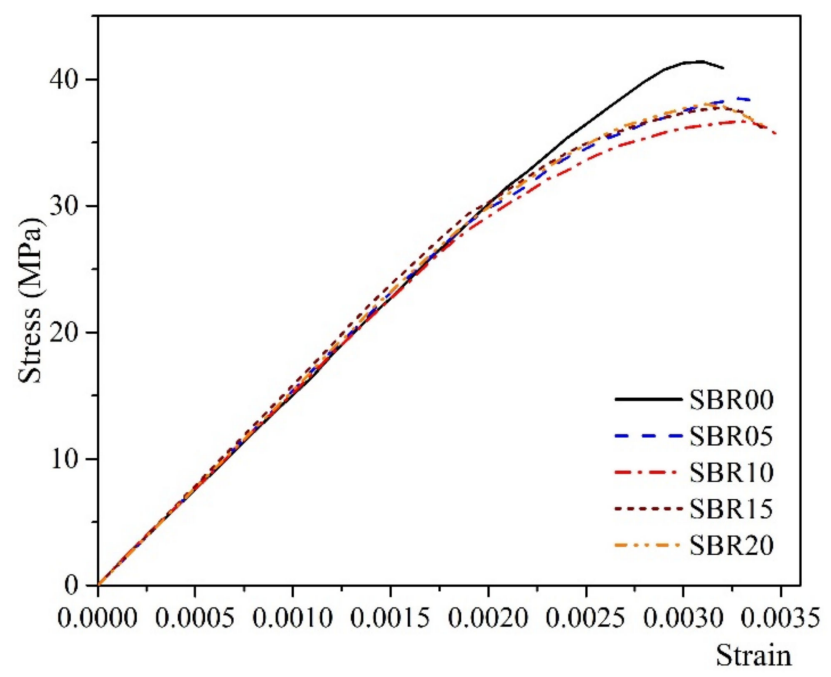

Figure 4. Constitutive curves of the SBR latex-modified cement paste at 28 days.

Table 3. Results from the compressive strength test and the Charpy impact test at 28 days.

\begin{tabular}{cccccc}
\hline Name & SBR00 & SBR05 & SBR10 & SBR15 & SBR20 \\
\hline \multirow{2}{*}{ Compressive strength $(\mathrm{MPa})$} & 41.51 & 38.54 & 36.7 & 37.75 & 38.29 \\
Toughness $\left(\mathrm{J} / \mathrm{m}^{3}\right)$ & $(3.191)$ & $(3.077)$ & $(1.801)$ & $(1.005)$ & $(1.743)$ \\
Energy absorption capacity & $74,725.0$ & $79,970.2$ & $81,586.6$ & $80,797.6$ & $80,138.7$ \\
$\left(\mathrm{~J} / \mathrm{m}^{2}\right)$ & $12,991.5$ & $14,848.1$ & 18,582 & $17,483.1$ & $17,021.5$ \\
& $(778.1)$ & $(982.1)$ & $(792)$ & $(956.7)$ & $(816.3)$ \\
\hline
\end{tabular}

The values in parentheses are standard deviation.

As can be seen from Figure 3, with $\mathrm{P} / \mathrm{C}$ ratios less than $10 \%$, the compressive strength tended to decrease. In contrast, the compressive strength showed a slight increase with the $\mathrm{P} / \mathrm{C}$ ratios higher than $10 \%$. However, the compressive strength of the modified paste was lower than that of the control paste. Compared to the result of the control paste, there was a decrease of $12 \%$ in the compressive strength when modifying cement paste by the $\mathrm{P} / \mathrm{C}$ of $10 \%$. From Figure 4 and Table 3, the benefit of adding polymer into the cement paste is shown, as it increases the strain of the hardened cement paste and leads to an increase in the toughness of the cementitious materials. According to the theory of Timoshenko [35], toughness can be calculated by the area under the constitutive curve of the material. Following that approach, the results from Table 3 show that an increase in toughness 
corresponded with an increase in $\mathrm{P} / \mathrm{C}$ ratios less than $10 \%$, and with $\mathrm{P} / \mathrm{C}$ ratios higher than $10 \%$, the toughness slowly decreased. The observations from the compressive strength test at 28 days showed an agreement with the findings from the works of Wang et al. [31,32] on SBR latex-modified mortar. As demonstrated from their works, the mechanical properties of the polymer-modified cement-based materials are dependent on their phase states. The microstructure of the matrix changes when the polymer films are formed and when the hydration process is operated. In that case, the interpenetrating structure of the matrix is formed, which increases the matrix, restrains the tiny cracks, and leads to an improvement in the toughness of the matrix. However, when the interpenetrating structure is fully formed and the polymer film becomes thicker, the higher $\mathrm{P} / \mathrm{C}$ ratios do not show their role in further improvement of the matrix properties. This can be pointed out with the $\mathrm{P} / \mathrm{C}$ ratio of $10 \%$. It is also worth mentioning that the SBR film has a very high toughness itself, thus the addition of SBR latex can contribute to improving the toughness of the matrix. As also observed from the works of Wang et al., SBR latex has lower strength compared to that of cement-based materials. In addition, adding SBR into cement-based materials increases the pore structure of the matrix and then reduces the bulk density. The increase in the ettringite content and decrease in calcium hydroxide content for the $\mathrm{P} / \mathrm{C}$ ratios higher than $10 \%$ led to an increase in the strength of the paste [26]. However, the complexity of the changes in the microstructure of the matrix, such as an increase in the porosity or thickening of the polymer film, or even adding the polymer, also affects the cement hydration. Thus it might reduce the result of the matrix strength.

\subsection{Impact Resistance}

Due to the completely broken states of all specimens after testing, the observations from the Charpy test were acceptable. Figure 5 and Table 3 show the results of the energy absorption capacity $\left(\mathrm{J} / \mathrm{m}^{2}\right)$ obtained from the average value of five specimens for each $\mathrm{P} / \mathrm{C}$ ratio. From an overall perspective, the energy absorption capacity of the SBR latexmodified cement paste increases with the increase in curing time. The time and the wet curing conditions might affect the creation of the polymer film as well as the hydration process of cement. A significant increase in energy absorption capacity of the SBR latexmodified cement paste was observed with the $\mathrm{P} / \mathrm{C}$ ratio increase from 0 to $10 \%$ over the three curing ages of the study. The observations from 7 days showed a significant increase in the energy absorption capacity of the pastes containing the $\mathrm{P} / \mathrm{C}$ ratios from 0 to $10 \%$, then a decreasing trend was observed for that of the pastes containing the $\mathrm{P} / \mathrm{C}$ ratios from 10 to $20 \%$. For instance, the increases of $24,76,58,49 \%$ were observed for the pastes containing the $\mathrm{P} / \mathrm{C}$ ratios from 5 to $20 \%$, respectively. At 14 days, the energy absorption capacity showed a similar trend with that at 7 days for the pastes containing the $\mathrm{P} / \mathrm{C}$ ratios from 0 to $10 \%$. In contrast, a slight decrease was observed when the $\mathrm{P} / \mathrm{C}$ ratio was from 10 to $15 \%$, then increased slightly from 15 to $20 \%$. The increases of $17,43,35,38 \%$ were reported for the pastes contain the $\mathrm{P} / \mathrm{C}$ ratios from 5 to $20 \%$, respectively. As can be observed from the result at 28 days, using the SBR latex in modifying cement paste showed its benefit by improving the energy absorption capacity of this material. There was a significant increase in the energy absorption capacity when the $\mathrm{P} / \mathrm{C}$ ratios increased from 0 to $10 \%$, and the observation showed an increase of 21 and $43 \%$ with the $\mathrm{P} / \mathrm{C}$ ratio from 5 and $10 \%$, respectively, compared to that of the control paste. Then the slight decreases of 43,34 , and $31 \%$ for the pastes containing the $\mathrm{P} / \mathrm{C}$ ratios of 10,15 , and $20 \%$ were observed, respectively.

The observations from the Charpy test accord with the results of toughness as presented above. They increase when the $\mathrm{P} / \mathrm{C}$ ratio increases from 0 to $10 \%$, and with the other $\mathrm{P} / \mathrm{C}$ ratios higher than $10 \%$, there are no further improvements. The $\mathrm{P} / \mathrm{C}$ ratio of $10 \%$ can be seen as an optimal ratio for observing the highest energy absorption capacity as well as toughness of SBR latex-modified cement paste. 


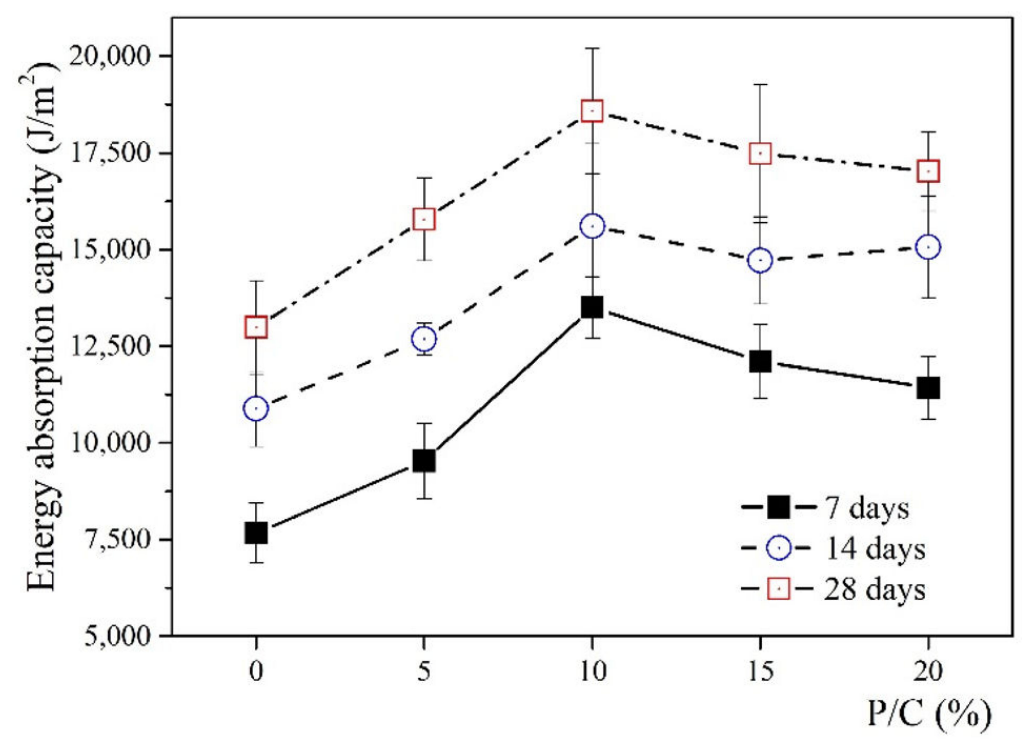

Figure 5. Influence of SBR latex on the energy absorption capacity of the cement paste at different ages of curing.

As a comparison with the above observations at 28 days, with the increase in the $\mathrm{P} / \mathrm{C}$ ratio from 0 to $10 \%$, there is an increase in the energy absorption capacity and a decrease in the compressive strength. In contrast, with the other $\mathrm{P} / \mathrm{C}$ ratios higher than $10 \%$, an inversed tendency is observed. Therefore, it can be inferred that there is an inversed relationship between the energy absorption capacity and the compressive strength of the SBR latex-modified cement paste at the age of 28 days. The relationship between them is shown in Figure 6 with a coefficient of determination $\left(R^{2}\right)$ of 0.9718 . Where I and $f_{c}^{\prime}$ are the energy absorption capacity $\left(\mathrm{J} / \mathrm{m}^{2}\right)$ and the compressive strength at 28 days (MPa) of the SBR latex-modified cement paste, respectively.

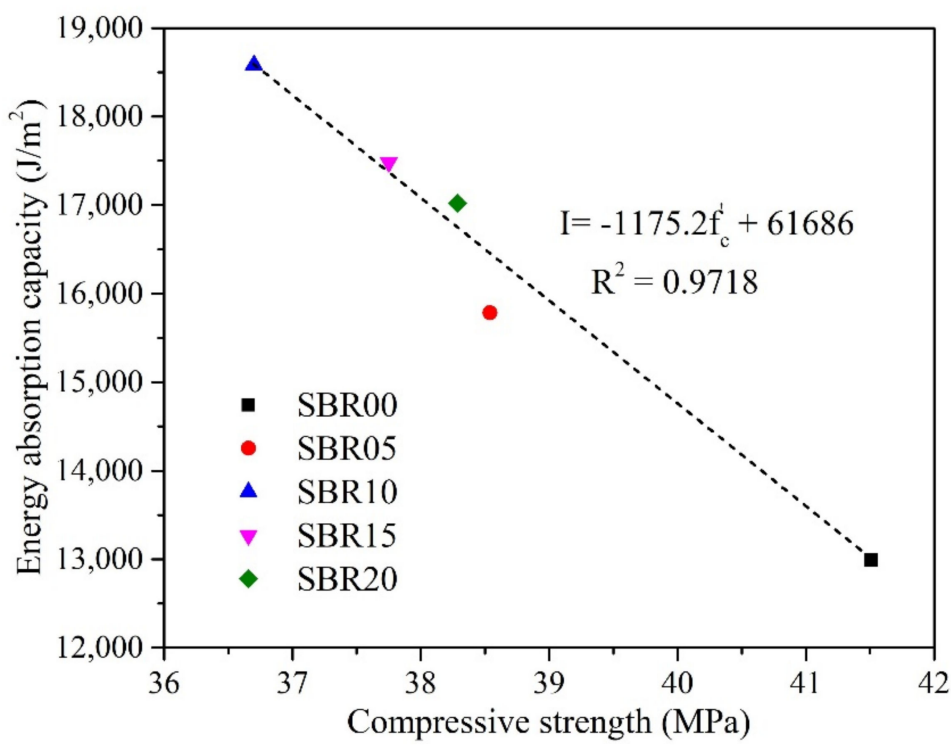

Figure 6. Relationship between compressive strength and energy absorption capacity of SBR latexmodified cement paste at 28 days.

\subsection{Weibull Distribution Analysis of the Charpy Impact Test}

The literature review shows that the result from the impact test fit with the twoparameter Weibull distribution $[36,37]$. Following that approach, in this study, the two- 
parameter Weibull distribution was utilized to examine the reliability of the results from the Charpy impact test.

From [38], the probability distribution function $f(x)$ and the cumulative density function $F_{X}(x)$ are denoted as below:

$$
\begin{gathered}
f(x)=\frac{k}{u-\varepsilon}\left(\frac{x-\varepsilon}{u-\varepsilon}\right)^{k-1} e^{-\left(\frac{x-\varepsilon}{u-\varepsilon}\right)^{k}} \\
F_{X}(x)=1-e^{-\left(\frac{x-\varepsilon}{u-\varepsilon}\right)^{k}}
\end{gathered}
$$

where $x$ is the specific value of random variables (in this present work it is the energy absorption capacity-I); $k$ is the shape parameter or Weibull slope; $u$ is the scale parameter; $\varepsilon$ is the location parameter or minimum life. Assuming that $\varepsilon=0$ for impact application [37], Equations (1) and (2) become:

$$
\begin{gathered}
f(x)=\frac{k}{u}\left(\frac{x}{u}\right)^{k-1} e^{-\left(\frac{x}{u}\right)^{k}} \\
F_{X}(x)=1-e^{-\left(\frac{x}{u}\right)^{k}}
\end{gathered}
$$

The probability of survivorship is given by [38]:

$$
L_{X}(x)=1-F_{X}(x)=e^{-\left(\frac{x}{u}\right)^{k}}
$$

Taking logarithms of both sides of Equation (5) gives.

$$
\ln \left[\ln \left(\frac{1}{L_{X}}\right)\right]=k \ln (x)-k \ln (u)
$$

Therefore, Equation (6) can be used for verifying the statistical distribution of the energy absorption capacity (I) of three studied groups of specimens following the twoparameter Weibull distribution. The data of energy absorption capacity were sorted from smallest to largest and the empirical survivorship function can be obtained as:

$$
L_{X}=1-\frac{i}{N+1}
$$

where $i$ is the order number and $N$ is the total number of specimens for each studied group.

Following the works [36,37], the linear relationship between $\ln \left[\ln \left(1 / L_{X}\right)\right]$ and $\ln x$ showed the suitability of utilizing the two-parameter Weibull distribution to create statistical data of the energy absorption capacity. Then, the regression coefficients $(k, k \ln u)$ and the correlation coefficient $\mathrm{R} 2$ can be derived by linear analysis.

Figure 7 and Table 4 show the variation in $\ln \left[\ln \left(1 / L_{X}\right)\right]$ and $\ln x$ for three groups of cement paste specimens with different curing times. As in the above discussion, the linear relationship between $\ln \left[\ln \left(1 / L_{X}\right)\right]$ and $\ln x$ is clarified. As a result, the two-parameter Weibull distribution is suitable for the description of the energy absorption capacity from the Charpy impact test. 


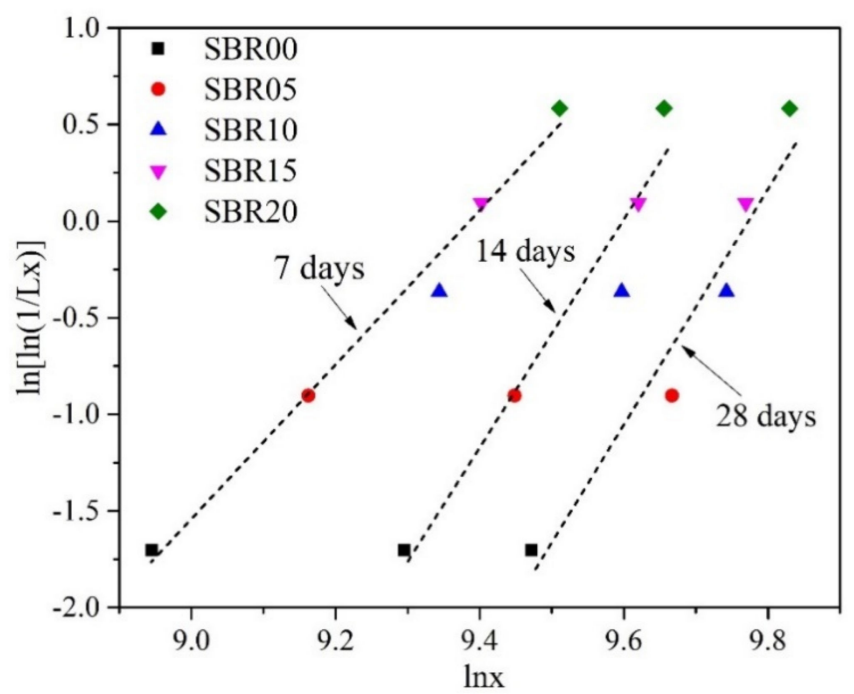

Figure 7. Weibull distribution of the energy absorption capacity (I).

Table 4. Linear regression coefficients of energy absorption capacity of the Weibull distribution.

\begin{tabular}{cccc}
\hline $\begin{array}{c}\text { Curing Time } \\
\text { (days) }\end{array}$ & $\begin{array}{c}\text { Regression Coefficient } \\
(\boldsymbol{k})\end{array}$ & $\begin{array}{c}\text { Regression Coefficient } \\
(\boldsymbol{k} \mathbf{l n} \boldsymbol{u})\end{array}$ & $\begin{array}{c}\text { Correlation } \\
\text { Coefficient }\left(\mathbf{R}^{\mathbf{2}}\right)\end{array}$ \\
\hline 7 & 3.951 & 37.092 & 0.984 \\
14 & 5.724 & 54.971 & 0.938 \\
28 & 6.224 & 60.805 & 0.942 \\
\hline
\end{tabular}

\section{Conclusions}

The influence of SBR latex polymer with different $\mathrm{P} / \mathrm{C}$ ratios on the energy absorption capacity of ordinary Portland cement was investigated in this study. The following conclusions may be drawn:

With $\mathrm{P} / \mathrm{C}$ ratios less than 10\%, increases in toughness and decreases in compressive strength are observed. In contrast, with $\mathrm{P} / \mathrm{C}$ ratios over $10 \%$, the observations show an inversed tendency.

The energy absorption capacity of the SBR latex-modified cement paste increases with the increase in the curing times from 7,14 , and, 28 days, as well as with the increase in the $\mathrm{P} / \mathrm{C}$ ratios from $0,5,10,15$, and $20 \%$. The energy absorption capacity of the SBR latex-modified cement paste increases significantly when the $\mathrm{P} / \mathrm{C}$ ratio increases from 0 to $10 \%$. With other $\mathrm{P} / \mathrm{C}$ ratios higher than $10 \%$, there are no further improvements. The $\mathrm{P} / \mathrm{C}$ ratio of $10 \%$ is the optimal ratio for observing the highest energy absorption capacity of the SBR latex-modified cement paste, i.e., an increase of $43 \%$ compared to that of the control paste is observed.

An equation is found to describe the inversed relationship between the energy absorption capacity and the compressive strength of the SBR latex-modified cement paste at 28 days. As a result, the energy absorption capacity of the SBR latex-modified cement paste at 28 days can be analyzed or predicted by the compressive strength results, regardless of the $\mathrm{P} / \mathrm{C}$ ratios.

The energy absorption capacity data observed from the Charpy impact test are fit with the two-parameter Weibull distribution.

The observations from this study can be a good reference for applying the SBR latex polymer-modified cement material for impact-resisting members, such as railway sleepers, blast-resisting members, cover members, and so on. 
Author Contributions: Conceptualization, J.J.K.; methodology, J.J.K. and T.N.M.N.; software, T.N.M.N.; validation, J.J.K.; formal analysis, T.N.M.N.; investigation, J.J.K.; data curation, J.J.K. and T.N.M.N.; writing—original draft preparation, T.N.M.N.; writing—review and editing, J.J.K.; visualization, J.J.K.; supervision, J.J.K.; project administration, J.J.K.; funding acquisition, J.J.K. All authors have read and agreed to the published version of the manuscript.

Funding: This research was funded by Kyungnam University Foundation Grant, 2018.

Institutional Review Board Statement: Not applicable.

Informed Consent Statement: Not applicable.

Data Availability Statement: The data presented in this study are available on request from the corresponding author.

Conflicts of Interest: The authors declare no conflict of interest.

\section{References}

1. Neville, A.M. Properties of Concrete, 5th ed.; Prentice Hall: Hoboken, NJ, USA, 2005.

2. Mehta, P.K.; Monteiro, P.J.M. Concrete: Microstructure, Properties, and Materials, 4th ed.; McGraw-Hill Education: New York, NY, USA, 2006.

3. Yang, J.; Peng, G.-F.; Zhao, J.; Shui, G.-S. On the explosive spalling behavior of ultra-high performance concrete with and without coarse aggregate exposed to high temperature. Constr. Build. Mater. 2019, 226, 932-944. [CrossRef]

4. Jamnam, S.; Maho, B.; Techaphatthanakon, A.; Sonoda, Y.; Yoo, D.-Y.; Sukontasukkul, P. Steel fiber reinforced concrete panels subjected to impact projectiles with different caliber sizes and muzzle energies. Case Stud. Constr. Mater. 2020, 13, e00360. [CrossRef]

5. Nataraja, M.; Dhang, N.; Gupta, A. Statistical variations in impact resistance of steel fiber-reinforced concrete subjected to drop weight test. Cem. Concr. Res. 1999, 29, 989-995. [CrossRef]

6. Khosravani, M.R.; Weinberg, K. A review on split Hopkinson bar experiments on the dynamic characterisation of concrete. Constr. Build. Mater. 2018, 190, 1264-1283. [CrossRef]

7. Francois, D.; Pineau, A. From Charpy to Present Impact Testing, 1st ed.; Elsevier Science: Amsterdam, The Netherlands, 2002; Volume 30.

8. ISO 148-1:2016. Metallic Materials—Charpy Pendulum Impact Test; International Organization for Standardization: Geneva, Switzerland, 2009.

9. ASTM E23-18. Standard Test Methods for Notched Bar Impact Testing of Metallic Materials; ASTM International: West Conshohocken, PA, USA, 2018.

10. ISO 179-1:2010. Plastics—Determination of Charpy Impact Properties; International Organization for Standardization: Geneva, Switzerland, 2010.

11. ASTM D6110-18. Standard Test Method for Determining the Charpy Impact Resistance of Notched Specimens of Plastics; ASTM International: West Conshohocken, PA, USA, 2018.

12. Pereira, A.C.; Monteiro, S.N.; de Assis, F.S.; Margem, F.M.; da Luz, F.S.; Braga, F.D.O. Charpy impact tenacity of epoxy matrix composites reinforced with aligned jute fibers. J. Mater. Res. Technol. 2017, 6, 312-316. [CrossRef]

13. Macke, T.; Quenisset, J.; Neuilly, D.; Rocher, J.; Naslain, R. A comparative study of the impact behavior of ceramic matrix composites. Compos. Sci. Technol. 1990, 37, 267-278. [CrossRef]

14. Tanks, J.; Sharp, S.; Harris, D. Charpy impact testing to assess the quality and durability of unidirectional CFRP rods. Polym. Test. 2016, 51, 63-68. [CrossRef]

15. Thomas, R.J.; Sorensen, A.D. Charpy Impact Test Methods for Cementitious Composites: Review and Commentary. J. Test. Eval. 2018, 46, 2422-2430. [CrossRef]

16. Hakamy, A.; Shaikh, F.U.A.; Low, I.M. Thermal and mechanical properties of hemp fabric-reinforced nanoclay-cement nanocomposites. J. Mater. Sci. 2014, 49, 1684-1694. [CrossRef]

17. Liu, Z.; Cui, Q.; Li, Q. Properties of GRC Modified by Emulsion. Presented at the GRCA 2015 Congress, Dubai, United Arab Emirates, 19-21 April 2015; International Glassfibre Reinforced Concrete Association: Hampton, UK, $2015 ;$ p. 14.

18. Yu, R.; Spiesz, P.; Brouwers, H. Static properties and impact resistance of a green Ultra-High Performance Hybrid Fibre Reinforced Concrete (UHPHFRC): Experiments and modeling. Constr. Build. Mater. 2014, 68, 158-171. [CrossRef]

19. Cresson, L. Improved Manufacture of Ruber Road-Acting, Rubber-Flooring, Rubber-Tiling or Other Rubber-Lining. British Patent 191, 1923.

20. Lefebure, V. Improvements in or Relatingto Concrete, Cements, Plasters and the Like. British Patent 217, 1924.

21. Ohama, Y. Polymer-based admixtures. Cem. Concr. Compos. 1998, 20, 189-212. [CrossRef]

22. Su, Z.; Bijen, J.; Larbi, J. Influence of polymer modification on the hydration of portland cement. Cem. Concr. Res. 1991, 21, 242-250. [CrossRef]

23. Sakai, E.; Sugita, J. Composite mechanism of polymer modified cement. Cem. Concr. Res. 1995, 25, 127-135. [CrossRef] 
24. Cong-Sheng, J.; Tao, W.; Qing-Jun, D.; Shao-Long, H.; Fa-Zhou, W.; Jian, G.; Shu-Guang, H. Influence of polymer addition on performance and mechanical properties of lightweight aggregate concrete. Wuhan Univ. J. Nat. Sci. 2004, 9, 348-352. [CrossRef]

25. Xu, F.; Zhou, M.; Chen, J.; Ruan, S. Mechanical performance evaluation of polyester fiber and SBR latex compound-modified cement concrete road overlay material. Constr. Build. Mater. 2014, 63, 142-149. [CrossRef]

26. Wang, R.; Li, X.-G.; Wang, P.-M. Influence of polymer on cement hydration in SBR-modified cement pastes. Cem. Concr. Res. 2006, 36, 1744-1751. [CrossRef]

27. Diab, A.M.; ElYamany, H.E.; Ali, A.H. Experimental investigation of the effect of latex solid/water ratio on latex modified co-matrix mechanical properties. Alex. Eng. J. 2013, 52, 83-98. [CrossRef]

28. Qu, X.; Zhao, X. Influence of SBR latex and HPMC on the cement hydration at early age. Case Stud. Constr. Mater. 2017, 6, 213-218. [CrossRef]

29. Barluenga, G.; Hernández-Olivares, F. SBR latex modified mortar rheology and mechanical behaviour. Cem. Concr. Res. 2004, 34, 527-535. [CrossRef]

30. Sun, K.; Wang, S.; Zeng, L.; Peng, X. Effect of styrene-butadiene rubber latex on the rheological behavior and pore structure of cement paste. Compos. Part B Eng. 2019, 163, 282-289. [CrossRef]

31. Wang, R.; Wang, P.-M.; Li, X.-G. Physical and mechanical properties of styrene-butadiene rubber emulsion modified cement mortars. Cem. Concr. Res. 2005, 35, 900-906. [CrossRef]

32. Wang, R.; Lackner, R.; Wang, P.-M. Effect of Styrene-Butadiene Rubber Latex on Mechanical Properties of Cementitious Materials Highlighted by Means of Nanoindentation. Strain 2011, 47, 117-126. [CrossRef]

33. ASTM C150/C150M-20. Standard Specification for Portland Cement; ASTM International: West Conshohocken, PA, USA, 2020.

34. ASTM C109/C109M-20b. Standard Test Method for Compressive Strength of Hydraulic Cement Mortars (Using 2-in. or [50 mm] Cube Specimens); ASTM International: West Conshohocken, PA, USA, 2020.

35. Timoshenko, S.P.; Gere, J.M. Mechanics of Materials; PWS-Kent Publishing: Boston, MA, USA, 1984.

36. Gupta, T.; Sharma, R.K.; Chaudhary, S. Impact resistance of concrete containing waste rubber fiber and silica fume. Int. J. Impact Eng. 2015, 83, 76-87. [CrossRef]

37. Chen, X.-Y.; Ding, Y.-N.; Azevedo, C.M. Combined effect of steel fibres and steel rebars on impact resistance of high performance concrete. J. Central South Univ. 2011, 18, 1677-1684. [CrossRef]

38. Nowak, A.S.; Collins, K.S. Reliability of Structure; Thomas Casson, McGraw-Hill: New York, NY, USA, 2000. 